\title{
Diagnosing the success of the construction projects during the initial phases
}

\author{
Mostafa Ghazimoradi $^{a^{*}}$, Ali Kheyroddin ${ }^{\mathrm{b}}$ and Omid Rezayfar $^{\mathrm{c}}$
}

${ }^{a}$ Ph.D. Student of Construction Management, Semnan University, Semnan, Iran ${ }^{b}$ Professor, Department of Civil Engineering, Semnan University, Semnan, Iran ${ }^{c}$ Assistant Professor, Department of Civil Engineering, Semnan University, Semnan, Iran

C H R O N I C L E

Article history:

Received October 25, 2015

Received in revised format:

December 12, 2015

Accepted February 14, 2016

Available online

Februray 142016

Keywords:

Anticipation of success

Criterion

Factor

Construction project

Initial phase

Neural networks

\section{Introduction}

Since realization of organizational strategies depends on the success of projects, the issue of success is crucial for the entire stakeholders in every project. Therefore, having an instrument, which provides a vision of projects' future has always been a stakeholders' demand. An instrument with the ability of anticipating the future states of projects have several applications including monitoring of projects during their lifecycles and facilitation of decision making processes. As a result, existence of different stakeholders with various objectives in a project, not only is a challenging task in terms of providing a universal definition for entire stakeholders' succes, but also it has led to formation of criteria with different and sometimes paradoxical priorities in the view of stakeholders. This issue is also disturbing in terms of providing a general and precise model for anticipation of projects' success. On the other

* Corresponding author.

E-mail address: ghazimoradi.m@students.semnan.ac.ir (M. Ghazimoradi)

(C) 2016 Growing Science Ltd. All rights reserved.

doi: $10.5267 /$ j.dsl.2016.2.002 
hand, roughly long lifecycle of construction projects has led to introduction of errors into the results provided by anticipator models.

The purpose of the present research is to provide a model to forecast the level of realization of success criteria according to the level of realization of success factors at the initial phase.

\section{Review of Literature}

\subsection{Anticipation of project success}

In early 1900 s, the word success was, for the first time, academically introduced in the contexts of industry (Atkinson, 1999; Wit, 1988). The initial definitions were simple and qualitative. However, as the range of projects was expanded, more complicated definitions were developed with more deployed dimensions including both qualitative and quantitative concepts (Lavagnon, 2009). At first, the subject of assessment of success of finished projects and later, the subject of anticipation of projects which had not yet been started became the main subjects of researches in this context. Previous researches regarding anticipation of the success of projects, are ready to be categorized in terms of different perspectives irrespective of their selected method of anticipation:

- Researches who tried to provide a model for predicting a single criterion such as time, expense, etc. For instance, Hwang (2008) used a regression model to forecast expenses. Also in another research, Hwang (2011) tried to anticipate the expenses of projects through Time series.

- Researches who tried to provide a model for predicting several criteria through defining a variable dependent on several other independent variables. For instance, Lipke et al. (2009) anticipated the time and expenses of a project through application of EVM (earned value management) technic. Also, Kim and Reinschmidt (2010) provided a model to anticipate project success through the earned value management (EVM) method.

- Researches who tried to develop performance and efficiency through considering different concepts as the basis. For instance, Li et al. (2006) tried to anticipate projects' potentials for violation of time tables and approved budgets through defining a potential function for a project as well as application of Fuzzy logics. In another similar research, the same researchers developed a model for design and construction contracts through application of regression (Lam et al., 2008). In another research, Cheung et al. (2008) tried to anticipate the index of satisfactory settlement of disputes through application of Regression method. In addition, Cheng et al. (2006) developed a model for anticipation of project efficiency through neural networks.

On the other hand, several methods have been used for anticipation as follows,

- $\quad$ Time series (Hwang, 2011; Wong et al., 2007)

- Various regression methods (Cheung et al., 2010; Hwang, 2008; Wang \& Gibson, 2010)

- Neural networks (Cheung et al., 2006; Chua et al. 1997; Ko \& Cheng, 2007; Wang \& Gibson, 2010)

- Fuzzy logics (Ko \& Cheng, 2007; Li et al., 2006; Young \& Poon, 2013)

In previous researches, most researchers and authors have recommended future researchers to provide their anticipator models with respect to things like localization in other countries, application of more precise and simple methods and a model for different phases of a project (Bygballe et al., 2010; Chang et al., 2013; davis, 2013; Eigbe et al., 2014; Han et al., 2007; Han et al. , 2007; Petro \& Gardiner, 2015).

\subsection{Implementation phases of construction projects}

A project's lifecycle is a series of generally consecutive and occasionally overlapping phases whose names and numbers are defined by managerial needs of organization or organizations engaged with the project, project's nature and the contexts of application of project. Different phases of a project include subdivisions within a project which seek more control for effective management of completion of the 
main components of the project. Basically, different phases of a project are completed in an orderly and consecutive manner, however they can be overlapping in some projects too.

- Initial phase: this phase is an approval for the entire project. This phase includes whether a project should or should not start, estimates what has to be provided by the project, defines the overall goals of the project, defines customers' and managers and other engaged parties' overall expectations, defines the project's scope, selects the primary members of the project team, etc.

- Planning phase: this phase defines and corrects goals and implements the best alternatives for obtaining the goals which are expected from the project. This phase includes determination of required resources, refinement of project area, provides the list of activities, determines the best sequence, provides an efficient plan and budget for allocation of resources, obtains the required approvals, etc.

- Execution phase: coordination of people and other resources for execution of the program. This phase includes leadership of the project team, holding meetings with team members, communicating other important parties, trouble shooting, supplication of the entire required resources, etc.

- Control phase: ensuring that project's goals are realized through continuous monitoring and measurements in order to spot violations and to be able to take necessary corrective actions. This phase includes monitoring of performance and reporting violations, making corrective decisions, performance of necessary reprogramming, limited reformations, etc.

- Concluding phase: official acceptance of the project and advancing the project to a standard conclusion. This phase includes documentation of results, reassessing the process of project performance, reviewing experiences, writing the final reports, etc.

\subsection{Neural networks}

Nowadays, new methods of anticipation have been developed under the title of artificial intelligence (AI). AI is referred to systems which are able to manifest reactions similar to genuine humane reactions including perception of complex situations, simulation of thinking processes and humane reasoning methods, ability of knowledge acquisition and reasoning for problem solving.

Among different AI methods, neural networks is the most applied method for forecasting events. Neural networks are computational models which are able to determine the relationships between a system's input and output through a network of connected nodes. In these models, the level of activity of each of these connections is set according to chronological information (learning process) and ultimately, the model is able to explore the related laws between input and outputs whether being nonlinear and complex. Basically, a neural network includes the components of layers and different weights. Also the network behavior depends on the relation between participants, while there are three neuron layers in each neural network:

Input layer: raw information are received and fed into the network.

Hidden layers: performance of hidden layers is determined by the input and with respect to the weight of the relation between the input and hidden layers. The weight of the relation between input units and hidden layers determines the timing for a hidden layer to become active.

Output layer: the performance of the output layer depends on the performance of the hidden layer and the weight of the relation between hidden layers and the output layer.

In a neural network, every two layers are connected by weights or in fact, fittings. There are various types of fittings or connections in neural networks.

There are different types of artificial neural networks with respect to the direction of entrance of information and processing of those information are divided into different types including Feed- 
Forward Neural Networks; Recurrent Networks; Radial Basis Function Networks and Multilayer Perceptron Networks.

\section{The proposed model}

\subsection{Data collection}

With the aim of defining and collecting the entire required criteria for assessment of a totally successful project on one hand, and also recognition and collecting the required factors for obtaining complete success from the views of the entire stakeholders of a project on the other hand; exploratory studies were performed in three steps.

At the first step, with the aim of collecting the results of previous researches among different scientific references, library studies were performed and resultantly, a series of criteria and factors of success were collected. At the next step, by carrying out six semi-structured interviews with experts of research domain, and by the help of a number of pre-determined questions, 6 more criteria and 14 more factors were added to the research. At the final step, with the aim of purification of 23 criteria and 47 collected factors, through the application of Delphi method and by incorporating the suggestions of five experts holding a Ph. D. and with sufficient amounts of executive experiences, the number of criteria and factors were respectively reduced to 16 and 33 which were suitable for Iran's Local situations. For this purpose, a primary questionnaire was developed and respectively, filled by the aforementioned five experts.

For the purpose of obtaining the main research goal, which was to provide an anticipator model, factors and criteria were prioritized according to Iran's local situation. For this purpose, a questionnaire comprised of two main sections was developed and sent for experts of construction domain. In the first section, the importance of each of 16 criteria were questioned for full assessment of success of a project and in the second section, the importance level of each of the aforementioned 33 factors were questioned in terms of obtaining complete success at the initial phase. On this basis, respondents were asked to give their answers according to a scale of zero (non-important) to four (very important).

The population of the research included entire project managers and planning experts of construction companies in the city of Tehran, Iran. A number of 260 questionnaires were distributed among the population and among this number, 91 questionnaires were excluded as a result of not being collected back or not containing the required validity. Diagram number one manifests abundance according to executive organs as well as experience level of the population. In addition, the aforementioned 16 criteria and 33 factors are mentioned in tables 1 and 2.

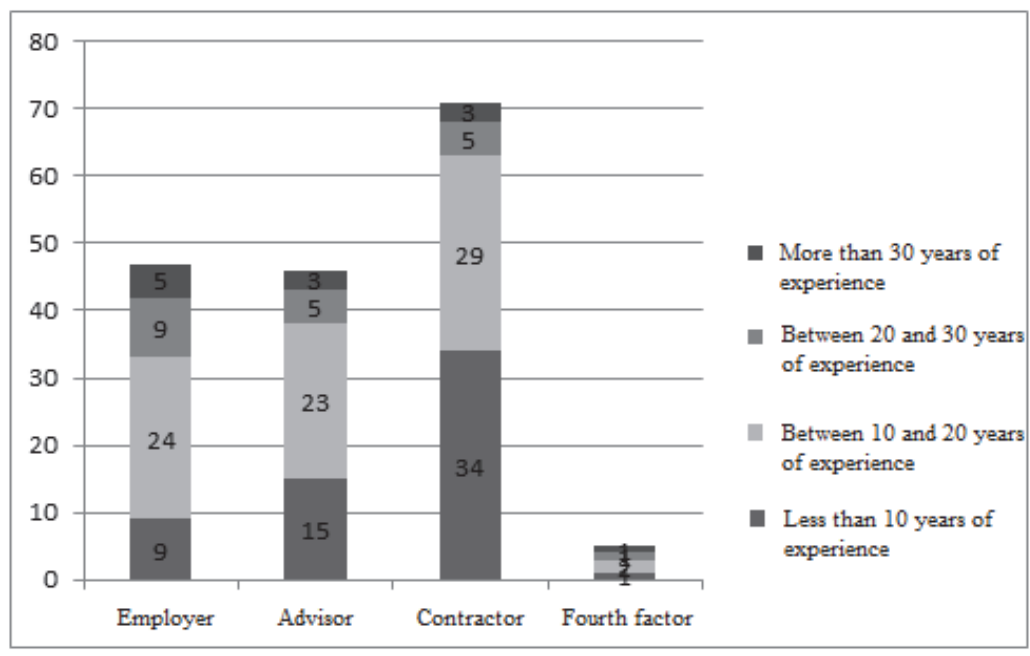

Fig. 1. Abundance according to executive organ and experience 


\subsection{Removing the outliers}

For removal of possible errors, outliers were identified after complete data collection. For this purpose, box diagrams were used as indexes for identification of outliers. These diagrams are used for manifestation of location, distribution and skewness of data. Through determining the first quarter (Q1), third quarter (Q3) and average, the IQR index was calculated for each and every one of the 16 criteria and 33 factors. According to this, each criterion or factor whose value does not fit the range of Eq. (2) is considered as outlier.

$$
I Q R=Q 3-Q 1,
$$

$$
\text { Q1-1.5IQR }<\text { values of criteria and factors }<Q 3+1.5 I Q R \text {. }
$$

On this basis, the data were inserted into the SPSS software and resultantly, outliers were identified. Among the existing 169 questionnaires, 4 or more than four outliers were identified in 34 of the questionnaires and the aforementioned questionnaires were deleted for the purpose of reduction of errors and increasing the strength of the test.

\subsection{Data analysis}

The Kolmogorov-Smirnoff test was run for determining the normality of data distribution. The resulted significance for entire factors and criteria was less than 0.05 and this manifests the significance of the test or in other words, data are not normally distributed. Therefore, there is not any possibility of using parametric tests. On the other hand, since research variables are qualitative, non-parametric tests were used for analysis of data.

In addition, for the entire 16 criteria and 33 factors, the value of Chi-Square test was calculated with significance of 0.000. Since this significance level is smaller than error value of $\alpha=0.05$, then we know that there exists a significant difference between ranks of each criteria. Tablel indicates the rankings of criteria according to Friedman tests' average ranking.

Table 1

\begin{tabular}{|c|c|c|c|c|c|c|}
\hline & Success Criteria & Freidman test & Average & Percentage & Score & $\begin{array}{r}\text { Standard } \\
\text { deviation }\end{array}$ \\
\hline $\mathrm{C} 1$ & Completing the project within the stipulated time & 11.3935 & 3.4438 & 74.23 & 582 & 0.606 \\
\hline $\mathrm{C} 2$ & Completing the project with the approved budget & 11.1065 & 3.3846 & 72.96 & 572 & 0.724 \\
\hline $\mathrm{C} 3$ & Compliance with the quality standards & 10.8876 & 3.3136 & 71.43 & 560 & 0.709 \\
\hline $\mathrm{C} 4$ & Achieving the specific objectives of the project & 10.6183 & 3.2663 & 70.41 & 552 & 0.798 \\
\hline $\mathrm{C} 5$ & Maximum achievement of safety indices & 10.2663 & 3.1834 & 68.62 & 538 & 0.850 \\
\hline C6 & $\begin{array}{l}\text { All stakeholders' satisfaction and fulfilling their demands } \\
\text { (employer, consultants, contractors, employees, personnel, } \\
\text { customers and suppliers, people) }\end{array}$ & 9.8964 & 3.1538 & 67.98 & 533 & 0.756 \\
\hline $\mathrm{C} 7$ & Achieving commercial interests / other interests & 9.0533 & 3.0118 & 64.92 & 509 & 0.764 \\
\hline $\mathrm{C} 8$ & Stability of management strategy & 8.6213 & 2.8817 & 62.12 & 487 & 0.950 \\
\hline C9 & Alignment with the environment & 8.4379 & 2.8343 & 61.10 & 479 & 0.998 \\
\hline $\mathrm{C} 10$ & In line with the goals and organizational strategies & 8.1953 & 2.8284 & 60.97 & 478 & 0.809 \\
\hline $\mathrm{C} 11$ & Motivation for future projects & 7.9408 & 2.7160 & 58.55 & 459 & 1.059 \\
\hline $\mathrm{C} 12$ & Increase the level of knowledge in the organization & 6.8107 & 2.5207 & 54.34 & 426 & 0.926 \\
\hline $\mathrm{C} 13$ & Minimal changes in project scope & 6.3669 & 2.4260 & 52.30 & 410 & 0.974 \\
\hline $\mathrm{C} 14$ & $\begin{array}{l}\text { The least effectiveness of the project from environmental } \\
\text { factors (political, economic, cultural) }\end{array}$ & 6.0680 & 2.3905 & 51.53 & 404 & 0.946 \\
\hline $\mathrm{C} 15$ & All participants' consideration of project success & 5.5355 & 2.2189 & 47.83 & 375 & 1.014 \\
\hline $\mathrm{C} 16$ & $\begin{array}{l}\text { Minimal changes in organizational culture due to the project } \\
\text { in the organization }\end{array}$ & 4.8018 & 2.1183 & 45.66 & 358 & 0.878 \\
\hline
\end{tabular}

Acquired ranks by criteria

Initial results of data analyses indicate the prioritization of three criteria of the iron triangle of the project namely as time, costs and quality. These criteria have acquired the highest ranks among other criteria. In addition, three criteria of Minimal changes in organizational culture due to the project in the organization, All participants' consideration of project success and the least effectiveness of the project from environmental factors (political, economic and cultural) have acquired the lowest of ranks among other criteria. 
In addition, a ranking similar to criteria is performed for required factors for obtaining success during the initial phase. The present ranking is based on the scores obtained from Friedman's test which is a non-parametric test.

Table 2

Collected success factors

\begin{tabular}{|c|c|c|c|c|c|c|}
\hline $\begin{array}{l}\text { Factor } \\
\text { symbol }\end{array}$ & Factors of success & $\begin{array}{l}\text { Freidman } \\
\text { test }\end{array}$ & $\begin{array}{l}\text { Std. } \\
\text { dev. }\end{array}$ & Score & Average & Percentage \\
\hline F1 & Awareness about the project & 22.15 & 0.691 & 596 & 3.53 & 88.17 \\
\hline F2 & Clarity of specifications of project & 21.54 & 1.053 & 560 & 3.31 & 82.84 \\
\hline F3 & Financial support reference & 21.46 & 0.977 & 560 & 3.31 & 82.84 \\
\hline F4 & Familiarity with geographical conditions & 20.67 & 0.887 & 565 & 3.34 & 83.58 \\
\hline F5 & $\begin{array}{l}\text { Forming a suitable team (finding the right people, providing the } \\
\text { necessary resources and providing a general perception of the } \\
\text { project) }\end{array}$ & 20.65 & 0.997 & 548 & 3.24 & 81.07 \\
\hline F6 & Creating specific and rational goals & 20.64 & 0.904 & 569 & 3.37 & 84.17 \\
\hline F7 & Selecting suitable counselors & 20.43 & 1.102 & 554 & 3.28 & 81.95 \\
\hline F8 & Emphasis on goals & 20.26 & 0.853 & 555 & 3.28 & 82.1 \\
\hline F9 & Having a planning process throughout the project's life cycle & 19.07 & 0.972 & 531 & 3.14 & 78.55 \\
\hline F10 & Supplication and allocation of financial sources & 18.95 & 1.048 & 534 & 3.16 & 78.99 \\
\hline F11 & $\begin{array}{l}\text { Qualification of knowledge and related experiences in employer } \\
\text { firm }\end{array}$ & 18.82 & 0.93 & 538 & 3.18 & 79.59 \\
\hline F12 & Familiarity with legal rules and regulations & 18.72 & 1.047 & 525 & 3.11 & 77.66 \\
\hline F13 & $\begin{array}{l}\text { Professional and behavioral skills of managers and engineering } \\
\text { teams }\end{array}$ & 18.41 & 0.946 & 518 & 3.07 & 76.63 \\
\hline F14 & Having executive experience & 18.31 & 0.94 & 516 & 3.05 & 76.33 \\
\hline F15 & Coordination with organization's strategies & 17.56 & 0.971 & 516 & 3.05 & 76.33 \\
\hline F16 & Teamwork (cooperation, confidence, trust, etc.) & 17.38 & 1.089 & 497 & 2.94 & 73.52 \\
\hline F17 & Selecting suitable contractors & 17.37 & 1.461 & 459 & 2.72 & 67.9 \\
\hline F18 & Suitable organizational structure at every step & 17.35 & 0.954 & 510 & 3.02 & 75.44 \\
\hline F19 & Manager's view according to views of public sector or private & 16.91 & 1.026 & 504 & 2.98 & 74.56 \\
\hline F20 & Support by senior managers & 16.9 & 1.234 & 460 & 2.72 & 68.05 \\
\hline F21 & Rate of inflation & 15.96 & 1.295 & 460 & 2.72 & 68.05 \\
\hline F22 & Suitable and timely flow of communications and information & 15.29 & 1.052 & 472 & 2.79 & 69.82 \\
\hline F23 & Continuous, clear and precise communications & 15.25 & 1.028 & 465 & 2.75 & 68.79 \\
\hline F24 & $\begin{array}{l}\text { Having a control system throughout the entire lifecycle of the } \\
\text { project }\end{array}$ & 14.48 & 1.096 & 443 & 2.62 & 65.53 \\
\hline F25 & Having an experience of execution of new and functional & 14.05 & 1.257 & 435 & 2.57 & 64.35 \\
\hline F26 & Providing privileges for senior managers & 13.94 & 1.072 & 446 & 2.64 & 65.98 \\
\hline F27 & Having suitable instruction structures during the project's lifecycle & 13.52 & 1.186 & 419 & 2.48 & 61.98 \\
\hline F28 & Supplying high quality material and suitable machineries & 13.51 & 1.46 & 390 & 2.31 & 57.69 \\
\hline F29 & Transformation management and preparedness for new & 13.36 & 1.216 & 424 & 2.51 & 62.72 \\
\hline F30 & Suitable reward systems & 12.37 & 1.243 & 395 & 2.34 & 58.43 \\
\hline F31 & Having an experience of application of quality control services & 12.32 & 1.206 & 386 & 2.28 & 57.1 \\
\hline F32 & Clarity and speed in providing technical solutions & 11.8 & 1.087 & 406 & 2.4 & 60.06 \\
\hline F33 & Attraction of labor force & 11.62 & 1.373 & 362 & 2.14 & 53.55 \\
\hline
\end{tabular}

Primary analysis of factors indicates the priority of three factors including awareness about the project, clarity of project specifications and financial support reference over other factors in the first or initial phase of the project. On the other hand, factors of attraction of labor force, clarity and speed in providing technical solutions and having an experience of application of quality control services have acquired the lowest of all ranks among other factors. The noteworthy point here is that the performed ranking indicates the priority of criteria and factors according to Iran's local conditions and situations during the initial phase of projects.

\subsection{Model presentation}

The presented model in this research is comprised of two main sections. The first section is concerned with development of a model for determining the relation between the input and collected output through application of neural networks and the second section is concerned with transformation of the obtained results for determining the value of anticipation for realization level of success criteria from 
the level of realization of success factors. Fig. 2 indicates the main levels of model in addition to subdivisions of each level.

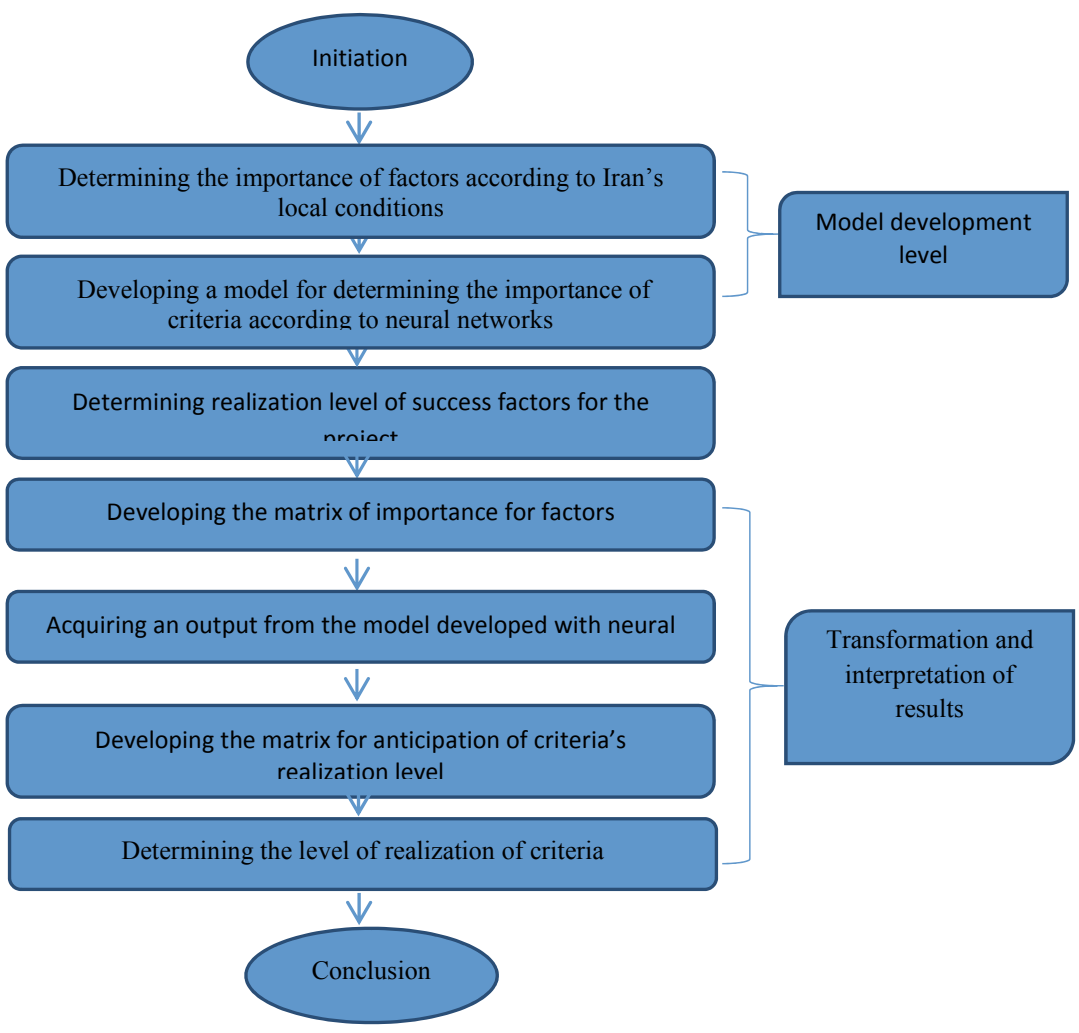

Fig. 2. Flowchart of levels of the proposed model

\subsection{Development of the Model}

As it was mentioned earlier, the collected data on one hand determine the importance of each factor for obtaining a hundred percent success during the initial phase of projects and on the other hand, determine the level of importance of each criterion from the perspective of every expert. On this basis, through application of neural networks, we can present a model for determining the relationships of the factors for the success and criteria of success. This model is the sum of views of experts regarding the relation between these elements. By using the neural Network toolbox in the software of MATLAB, a multilayer perceptron network was developed for the aforementioned model. For this purpose, the software was tested fifty times and the most optimized and precise model was selected. The selected model is a network with two hidden layers and respectively 50 and 16 neurons in each layer. The whole 33 inputs of this network indicate the importance of factors and its 16 outputs also indicate the importance of each criterion. The importance level of factors and criterions are reflected on a scale of 1 (non-important) to 5 (very important). Fig. 3 provides a view of the components of model.

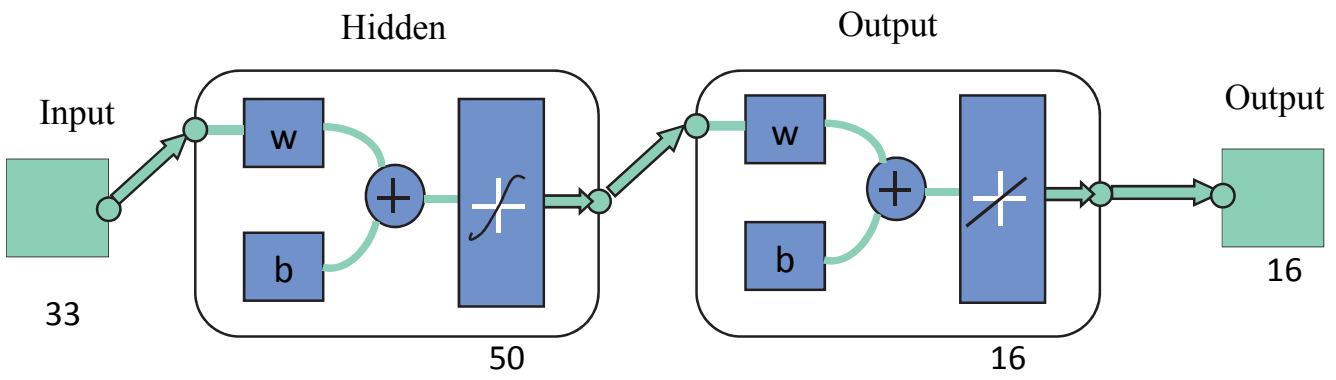

Fig. 3. A view of the model developed with neuron networks 
The number of inputs for the purpose of network testing and training was equal to the number of effective questionnaires as 134 series. Of this value, $70 \%$ is used for training, $10 \%$ is used for testing and $10 \%$ is used for validation of the model. Also the Bayesian Regularization algorithm was employed for development of this model.

Once the network was developed, the error level was calculated through Eq. (3).

$$
\text { Errors }=\text { targets-outputs }
$$

Highest error distribution is between the values of -0.11 and 0.2 . The error distribution diagram for the developed network is shown in figure 4.

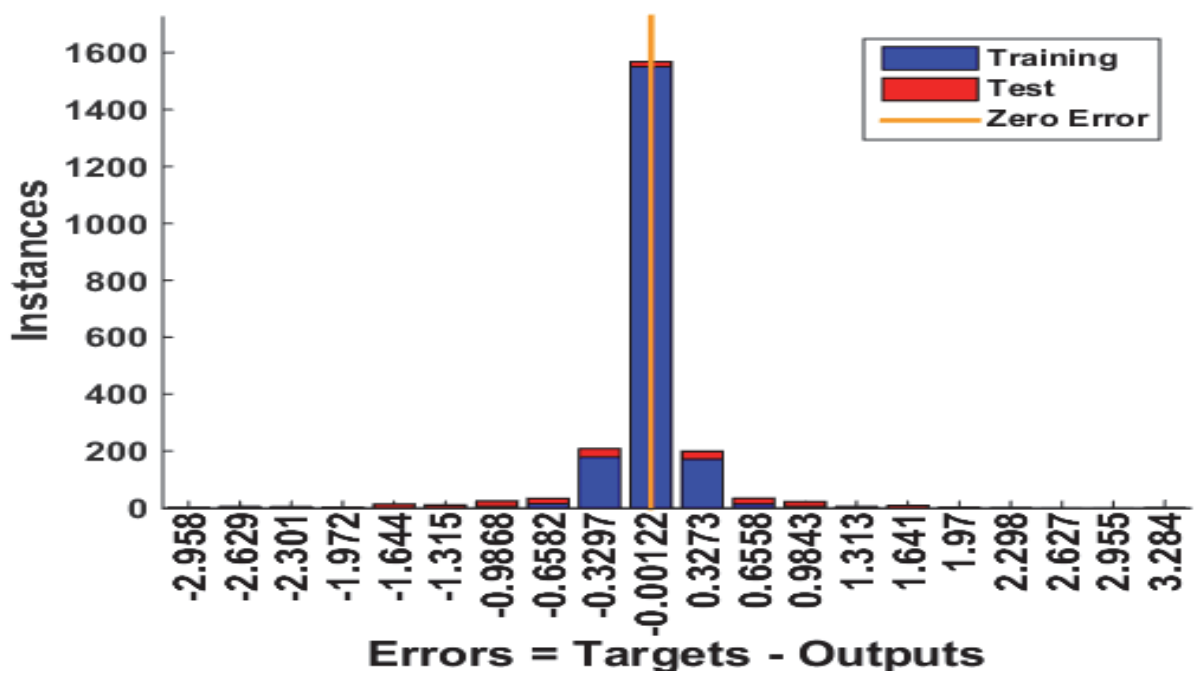

Fig. 4. Error distribution diagram

In addition, the model's performance index is equal to 0.0180 . This value was obtained in cycle 988 among 1000 training cycles. Fig. 5 indicates the changes of performance index during the network's training period.

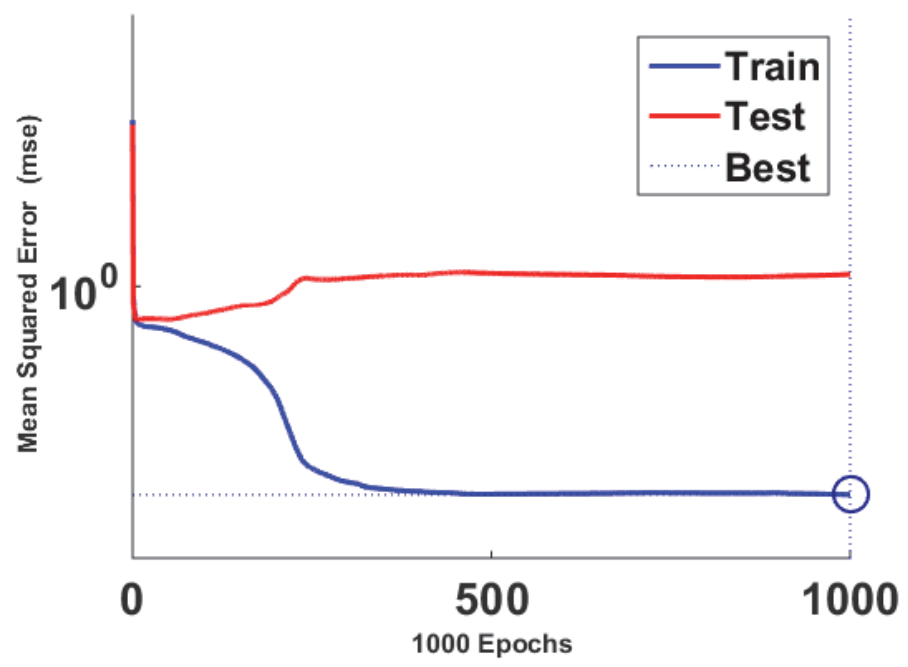

Fig. 5. The changes of performance index during the network's training period

Another important index in terms of neural networks, is the index of regression and for the proposed model, this value is equal to 0.9267 for entire inputs. Fig. 6 presents the processed regression diagram. 


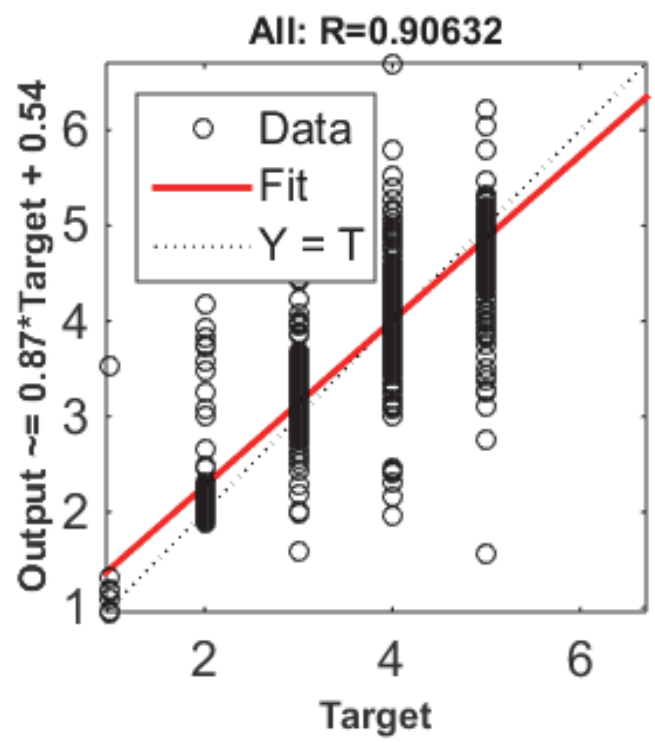

Fig. 6. network's regression diagram

The values of aforementioned indexes indicate the suitability and desirability of the precision of the proposed model. This means that this network is ready to be employed as a model for determining the importance of success factors according to the importance of success factors.

\subsection{Transformation and interpretation of results}

Since the purpose of this paper was to anticipate the level of realization of success criteria according to the level of realization of success factors, the next step is concerned with providing a method for implementation of the proposed model for obtaining this goal.

For realization of the aforementioned goal, this level includes four steps. The first step is concerned with reviewing and analyzing the existing conditions. For this purpose, 33 factors required for obtaining success should be analyzed and the level of realization of each of these factors should be determined according to Table 3.

\section{Table 3}

Guide to determination of factors' realization level

\begin{tabular}{ccc}
\hline No. & Level of realization & Score \\
\hline 1 & Not realized at all & 0 \\
2 & Almost not realized & $0-0.25$ \\
3 & Semi-realized & $0.25-0.5$ \\
4 & Almost completely realized & $0.5-0.75$ \\
5 & Completely realized & $0.75-1$ \\
\hline
\end{tabular}

The next step is concerned with putting the level of realization of each factor into effect. Eq. (4) indicates the effect of level of realization of each factor on their consequent importance.

$$
\left[\begin{array}{ccc}
\left(f_{1}\right)_{1} & \cdots & \left(f_{1}\right)_{134} \\
\vdots & \ddots & \vdots \\
\left(f_{33}\right)_{1} & \cdots & \left(f_{33}\right)_{134}
\end{array}\right]=\begin{gathered}
w_{1} \\
\cdots \\
w_{33}
\end{gathered} \cdot\left[\begin{array}{ccc}
\left(F_{1}\right)_{1} & \cdots & \left(F_{1}\right)_{134} \\
\vdots & \ddots & \vdots \\
\left(F_{33}\right)_{1} & \cdots & \left(F_{33}\right)_{134}
\end{array}\right]
$$

In Eq. (4), the matrix $F$ indicates the level of each factor's importance, the $W_{i}$ matrix indicates the level of realization for the $i$ factor and the $f$ matrix indicates the effect of conditions on importance of each factor. 
The third step is concerned with employing the matrix on the extracted model as the input. The model's output in this step is a $16 \times 134$ matrix.

The final step of this level is to recover the outputs of the model to the forecasting value of criteria fulfilling. For this purpose, at the first it is required to divide each entry of the output matrix of neural networks by its corresponding entry on the matrix of importance of criteria. Eq. (5) indicates the manner of calculation of level of realization of criteria.

$$
\left[\begin{array}{ccc}
\left(p_{1}\right)_{1} & \cdots & \left(p_{1}\right)_{134} \\
\vdots & \ddots & \vdots \\
\left(p_{33}\right)_{1} & \cdots & \left(p_{33}\right)_{134}
\end{array}\right]=\left[\begin{array}{ccc}
\left(c_{1}\right)_{1} & \cdots & \left(c_{1}\right)_{134} \\
\vdots & \ddots & \vdots \\
\left(c_{33}\right)_{1} & \cdots & \left(c_{33}\right)_{134}
\end{array}\right] /\left[\begin{array}{ccc}
\left(C_{1}\right)_{1} & \cdots & \left(C_{1}\right)_{134} \\
\vdots & \ddots & \vdots \\
\left(C_{33}\right)_{1} & \cdots & \left(C_{33}\right)_{134}
\end{array}\right]
$$

In this relation, the $p$ matrix is the matrix of anticipation of criteria's realization, the $c$ matrix is the network's output matrix and the $C$ matrix is the matrix of importance of criteria.

At the end, prediction values of each success criteria are evaluated. For this, average elements of each line of $\mathrm{p}$ matrix that is obtained from relation 6 , is as results of proposed model that is presented in this research.

$$
P_{j}=\frac{\sum_{\mathrm{i}=1}^{134} p_{i}}{134}
$$

where $P_{i}$ is the element of $i$ th line that is forecasted and $\mathrm{P}_{\mathrm{j}}$; which is the $j$ th criteria that is evaluated.

As is described before, $P$ is the amount for each criterion, which shows how many of them are realized. A 0 value for $P$ means no absolute amount and one for $P$ means complete amount. So, when the amount of $P$ for a criterion is equal to zero, forecasted result is weakness for the realization of that criterion.

Based on sensitivity analysis, on one hand, the first three criteria $\left(\mathrm{C}_{1}, \mathrm{C}_{2}\right.$, and $\left.\mathrm{C}_{3}\right)$ cover $34 \%$ of the variance of project success, but in the other hand, first five factors $\left(\mathrm{F}_{1}\right.$ until $\left.\mathrm{F}_{5}\right)$ cover $47 \%$ of the variance of essential factors to success, that these reflect the importance of these three criteria and five factors in projects.

Interpretation of $\mathrm{P}$ amount on the one hand, and satisfaction level for each criteria on the other hand are related to kind of users and Stakeholders of model. Accordingly, different Stakeholders with various strategies and with different kinds of priorities for all criteria can reach different results.

With $P$ values that are calculated and importance of each criteria, judging of project success can be predicted. This subject can be as suggestion for future research,

\subsection{Model validation}

Model validation was conducted to ensure that the constructed model in this research is generalizable to the population and not specific to the sample used in training.

First, $\mathrm{R}, \mathrm{R}^{2}$ and Mean Square Error (MSE) for the network are calculated, While $10 \%$ of the initial data were used to assess neural network of model. Results are shows in Table 4 . These results confirm high reliability of model.

Table 4

Performance Evaluation of model's neural network

\begin{tabular}{lccc}
\hline & $\mathrm{R}$ & $\mathrm{R}^{2}$ & $\mathrm{MSE}$ \\
\hline Neural Network of Model & 0.910 & 0.996 & 0.0412 \\
\hline
\end{tabular}

Also a diagnostic test was conducted and the residual plots of $R$ (being actual $C$ less the predicted $\mathrm{C}$ ) versus predicted $C$ showed a random distribution. This indicates that the normality assumption is valid. 


\subsection{Practical application}

This research proposed, developed and diagnosed the model that firms and stockholders can use to predict how successful their projects in Iran are likely to be based on different PM practices adopted. The project management practices revealed in the model could serve as a guide for them to adopt when operating in Iran's construction industry. The model is also useful to foreign firms that are assessing if they would like to take part or manage a project in Iran, because the likely outcome may be forecasted before they embark on the project.

\section{Conclusions}

In this research, a model based on neural networks was developed for anticipation of the success of construction projects depending on the level of realization of success factors during the initial phase of a project. The following could be pointed out as advantages of this model:

1- The basis of judgment for the proposed model is the inputs of the model, or in other words the level of realization of success factors during the initial phase of a project. This realization is based on abilities and potentials. On this basis this model can illustrate different situations in the future which may result in declination or approval of the project

2- The output of the anticipator model is the estimated value of each of 16 criteria. On this basis, different stakeholders can have their final judgment of success of the project with respect to realization level of prioritized criteria. This advantage is important since existence of difference in organizational strategies of various stakeholders of a single project lead to emergence of different views regarding prioritization of success criteria.

3- Application of neural networks in the proposed model has led to emergence of certain advantages and abilities such as high precision, ease of use and the ability of deduction for the model.

4- Ranking of aforementioned factors and criteria are according to Iran's local conditions. Therefore, ease of imposing changes on the model for implementing it in other regions is another advantage of the proposed model.

\section{References}

Atkinson, R. (1999). Project management: cost, time and quality, two best guesses and a phenomenon, its time to accept other success criteria.International journal of project management, 17(6), 337342.

Bygballe, L. E., Jahre, M., \& Swärd, A. (2010). Partnering relationships in construction: A literature review. Journal of purchasing and supply management, 16(4), 239-253.

Chang, A., Chih, Y. Y., Chew, E., \& Pisarski, A. (2013). Reconceptualising mega project success in Australian Defence: Recognising the importance of value co-creation. International Journal of Project Management, 31(8), 1139-1153.

Cheung, S. O., Wong, P. S. P., Fung, A. S., \& Coffey, W. V. (2006). Predicting project performance through neural networks. International Journal of Project Management, 24(3), 207-215.

Cheung, S. O., Yiu, T. W., \& Chan, H. W. (2009). Exploring the potential for predicting project dispute resolution satisfaction using logistic regression.Journal of Construction Engineering and Management, 136(5), 508-517.

Chua, D. K. H., Loh, P. K., Kog, Y. C., \& Jaselskis, E. J. (1997). Neural networks for construction project success. Expert Systems with Applications, 13(4), 317-328.

Davis, K. (2014). Different stakeholder groups and their perceptions of project success. International Journal of Project Management, 32(2), 189-201.

Eigbe, A. P., Sauser, B. J., \& Felder, W. (2015). Systemic analysis of the critical dimensions of project management that impact test and evaluation program outcomes. International Journal of Project Management, 33(4), 747-759. 
Eigbe, A. P., Sauser, B. J., \& Felder, W. (2015). Systemic analysis of the critical dimensions of project management that impact test and evaluation program outcomes. International Journal of Project Management, 33(4), 747-759.

Han, S. H., Kim, D. Y., \& Kim, H. (2007). Predicting profit performance for selecting candidate international construction projects. Journal of Construction Engineering and Management, 133(6), 425-436.

Hwang, S. (2009). Dynamic regression models for prediction of construction costs. Journal of Construction Engineering and Management, 135(5), 360-367.

Hwang, S. (2011). Time series models for forecasting construction costs using time series indexes. Journal of Construction Engineering and Management,137(9), 656-662.

Kim, B. C., \& Reinschmidt, K. F. (2010). Probabilistic forecasting of project duration using Kalman filter and the earned value method. Journal of Construction Engineering and Management, 136(8), 834-843.

Ko, C. H., \& Cheng, M. Y. (2007). Dynamic prediction of project success using artificial intelligence. Journal of construction engineering and management,133(4), 316-324.

Lam, E. W., Chan, A. P., \& Chan, D. W. (2008). Determinants of successful design-build projects. Journal of Construction Engineering and management, 134(5), 333-341.

Ika, L. A. (2009). Project success as a topic in project management journals.Project Management Journal, 40(4), 6-19.

Li, J., Moselhi, O., \& Alkass, S. (2006). Forecasting project status by using fuzzy logic. Journal of construction engineering and management, 132(11), 1193-1202.

Lipke, W., Zwikael, O., Henderson, K., \& Anbari, F. (2009). Prediction of project outcome: The application of statistical methods to earned value management and earned schedule performance indexes. International journal of project management, 27(4), 400-407.

Petro, Y., \& Gardiner, P. (2015). An investigation of the influence of organizational design on project portfolio success, effectiveness and business efficiency for project-based organizations. International Journal of Project Management, 33(8), 1717-1729.

Wang, Y. R., \& Gibson, G. E. (2010). A study of preproject planning and project success using ANNs and regression models. Automation in Construction, 19(3), 341-346.

De Wit, A. (1988). Measurement of project success. International journal of project management, 6(3), 164-170.

Wong, P. S., On Cheung, S., \& Hardcastle, C. (2007). Embodying learning effect in performance prediction. Journal of construction engineering and management, 133(6), 474-482.

Young, R., \& Poon, S. (2013). Top management support-almost always necessary and sometimes sufficient for success: Findings from a fuzzy set analysis. International journal of project management, 31(7), 943-957. 